in an urban hospital--Florida. MMWR 1990;39:718-722.

3. Centers for Disease Control. Nosocomial transmission of multidrugresistant tuberculosis among HIV-infected persons-Florida and New York, 1988-1991. MMWR 1991;40:585-591.

4. Centers for Disease Control. Guidelines for preventing the transmission of tuberculosis in health-care setting, with special focus on HIV-related issues. $M M W R$ 1990;39(RR-17).

5. Centers for Disease Control and Prevention. Guidelines for preventing the transmission of Mycobacterium tuberculosis in health-care facilities, 1994. MMWR 1994;43:1-132.

6. Manangan LP, Perrotta DM, Banerjee SN, Hack D, Simonds DN, Jarvis WR. Status of tuberculosis infection control programs at Texas hospitals, 1989 through 1991. Am I Infect Control 1997;25:229-235.

7. Stricof RL, Novick LF, DiFerdinando GT. Tuberculosis control in New York City hospitals. Am J Infect Control 1996;24:117-118. Abstract.

8. Cantwell MF, Snider DE, Cauthen GM, Onorato IM. Epidemiology of tuberculosis in the United States, 1985 through 1992. JAMA 1994;272:535-539.

9. Liu Z, Shilkret KL, Finelli L. Epidemiology of multidrug-resistant tuberculosis in New Jersey, 1991-1995. Presented at the 36th Interscience Conference on Antimicrobial Agents and Chemotherapy; September 15 18, 1996; New Orleans, LA. Abstract C119.

10. Tokars JI, Rudnick JR, Kroc K, Manangan L, Pugliese G, Huebner RE, et al. U.S. hospital mycobacteriology laboratories: status and comparison with state public health department laboratories. J Clin Microbiol 1996;34:680-685.
11. Centers for Disease Control and Prevention. Tuberculosis morbidityUnited States, 1996. MMWR 1997;46:695-700.

12. Centers for Disease Control and Prevention. Tuberculosis morbidityUnited States, 1995. MMWR 1996;45:365-370.

13. Jarvis WR. Nosocomial transmission of multidrug-resistant Mycobacterium tuberculosis. Am J Infect Control 1995;23:146-151.

14. Manangan LP, Simonds DN, Pugliese G, Kroc K, Banerjee SN, Rudnick JR, et al. Are U.S. hospitals making progress in implementing guidelines for prevention of Mycobacterium tuberculosis transmission? Arch Intern Med. 1998;158:1440-1444.

15. Maloney SA, Pearson ML, Gordon MT, Castillo RD, Boyle JF, Jarvis WR. Efficacy of control measures in preventing nosocomial transmission of multidrug-resistant tuberculosis to patients and health care workers. Ann Intern Med 1995;122:90-95.

16. Wenger PN, Otten J, Breeden A, Orfas D, Beck-Sague CM, Jarvis WR. Control of nosocomial transmission of multidrug-resistant Mycobacterium tuberculosis among health care workers and HIV-infected patients. Lancet 1995;345:235-240.

17. Stroud LA, Tokars JI, Grieco MH, Crawford JT, Culver DH, Edlin BR, et al. Evaluation of infection control measures in preventing the nosocomial transmission of multidrug-resistant Mycobacterium tuberculosis in a New York City hospital. Infect Control Hosp Epidemiol 1995;16:141147.

18. Occupational Safety and Health Administration, Department of Labor. Occupational exposure to tuberculosis; proposed rule (29 CFR Part 1910). Federal Register 1997:54160-54308.

\title{
Group A Streptococcus Outbreaks Linked to Healthcare Workers
}

\section{Gina Pugliese, RN, MS Martin S. Favero, PhD}

Group A streptococcus (GAS), a common cause of pharyngitis and uncomplicated skin and soft-tissue infections, can cause serious invasive infections (including necrotizing fasciitis and streptococcal toxic-shock syndrome [STSS]) and death. Since 1965 , at least 15 postoperative or postpartum GAS outbreaks attributed to asymptomatic carriage in healthcare workers (HCWs) have been reported. The CDC recently described two nosocomial outbreaks of GAS infection in Maryland and California during 1996 through 1997; the findings suggest that early infection control measures that include active surveillance may interrupt transmission and prevent morbidity and mortality.

In Maryland, seven patients with postpartum GAS infections were identified by hospital A. No patients died. A case-control study identified one $\mathrm{HCW}$ strongly associated with infections in patients. GAS isolates from the HCW and a patient isolate were typed by sequencing the variable portion of the M-protein gene (emm typing) and found to be identical. The HCW's wife, who was asymptomatic, had positive rectal and vaginal cultures for the same strain. HCW A and his wife were treated with oral vancomycin and rifampin. Surveillance cultures of HCW A have remained negative, and hospital A has had no additional cases.

In California, three previously healthy patients who had thyroid surgery at hospital B developed STSS; two of the patients died of GAS sepsis. Review of hospital B's microbiology records revealed no episodes of postoperative GAS infection during the 6 months before the outbreak. Surgeon A was the only $\mathrm{HCW}$ who had contact in the operating room with all three patients. Nasopharyngeal, throat, rectal, and vaginal cultures were obtained from the 41 staff members who worked in the operating room and the pre- or postoperative areas on the days of surgery for the patients. All cultures were negative, except a throat culture from one orderly that grew GAS. Surgeon A received self-initiated penicillin, before adequate cultures were obtained. Rifampin was added following adequate culturing. Throat cultures from surgeon A's household contacts were negative. GAS isolates from all three patients were $M$ type 1 and had indistinguishable restriction fragment-length polymorphism patterns. The orderly's GAS isolate was $M$ type STNS5. Surgeons A and B were restricted from patient care until each had completed a 10-day course of penicillin and rifampin. No further postoperative GAS infection has occurred in hospital B.

To prevent additional nosocomial GAS infections, enhanced surveillance and epidemiological investigation are warranted following one episode of nosocomial GAS infection on a surgical or obstetric ward. Isolates from infected patients should be stored. HCW screening should include all those present during the procedures (including those performing vaginal examinations before delivery and changing dressings on open wounds). Any $\mathrm{HCW}$ culture-positive for GAS should refrain from patient care for the first 24 hours of antimicrobial treatment. The CDC also recommends obtaining cultures from household contacts of implicated carriers to identify and treat potential reservoirs for reinfection. Because carriage may recur, implicated carriers should be monitored with periodic surveillance cultures for 1 year after treatment.

FROM: Centers for Disease Control and Prevention. Nosocomial group A streptococcal infections associated with asymptomatic health-care workers-Maryland and California, 1997. MMWR 1999;48(8):163-166. 